\title{
O CEGO E A CIDADE
}

\author{
SANTOS, Deborah Macêdo dos (1); \\ PONTES, Thiago Bessa (2); \\ LANDIM, Camila Bandeira Pinheiro (3). \\ (1) Universidade Federal do Cariri, Mestre \\ e-mail:deborah.santos@ufca.edu.br \\ (2) Universidade Federal do Cariri, Mestre \\ e-mail:thiago.bessa@ufca.edu.br \\ (3) Universidade de Fortaleza, Mestre \\ e-mail:camilabandeira@campus.ul.pt
}

\begin{abstract}
RESUMO
A organização urbana da cidade pode contribuir ou não para as interações humanas, inclusão social e autonomia das pessoas com necessidades especiais. Contudo, durante muito tempo as cidades não foram planejadas para acolher a diversidade, tornando-se até um espaço segregador de algumas minorias, como é o caso dos deficientes visuais. Este artigo objetiva apresentar uma revisão da literatura e sua evolução a respeito de como os elementos da arquitetura da cidade podem contribuir para a inclusão do deficiente visual e qual a maneira mais adequada de reproduzi-los.
\end{abstract}

Palavras chave: acessibilidade, deficiente visual, arquitetura da cidade.

\begin{abstract}
The urban organization of the city can contribute os not for human interactions, social inclusion and autonomy of people with special needs. However, for many time the cities were not designed to integrates the diversity, being segregational for some minorities, such as visually impaired. This article presents a literature review and its evolution according to how the architectonic elements can contribute to include the visually impaired people and also how reproduce it.
\end{abstract}

Keywords: acessibility; visually impaired; architecture of city.

\section{INTRODUÇÃO}

A organização urbana da cidade pode contribuir ou não para as interações humanas, inclusão social e autonomia das pessoas com necessidades especiais. Contudo, durante muito tempo as cidades não foram planejadas para acolher a diversidade, tornando-se até um espaço segregador de algumas minorias.

Amiralian (1997) dissertou, em seu livro, sobre o cotidiano de casos de deficientes visuais, eventualmente percebe-se a sua relação com a espacialidade.

"Joana conta que em sua cidade não fazia nada, ajudava no serviço de casa e saía com os irmãos" AMIRALIAN, p. 119, 1997 


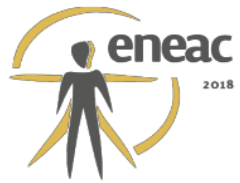

Joana era uma deficiente visual que, como os outros em suas condições, saia apenas acompanhada, pois não possuía autonomia suficiente para viver nos espaços públicos.

Sabe-se que os cegos possuem plena capacidade cognitiva e podem naturalmente fazer uso dos espaços públicos. Desde que sejam estimulados a isso e que as cidades sejam projetadas à luz das técnicas e acessibilidade.

Essa acessibilidade deve estar associada à estruturação urbana que se estabelece em diferentes contextos para que, assim, haja de fato a possibilidade de exercício do direito à cidade." PEREIRA 2008

Talvez o autor precursor desta nova corrente filosófica, que acredita na cidade, não apenas como fruto de um trabalho estético, mas como um produto de trabalho interdisciplinar com conhecimentos transversais também a sociologia, a antropologia, a geografia e outras ciências, foi o arquiteto Kevin Lynch (1998) que considerou a imagem da cidade como o resultado das percepções de diversos sentidos.

"Estruturar e identificar o meio ambiente é uma atividade vital de todo o animal móvel. São muitas as espécies de orientação usadas: A sensação visual da cor, da forma, do movimento ou polarização da luz, assim como outros sentidos, tais como o cheiro, o ouvido, o tacto, a cinestesia, a noção de gravidade e talvez os campos magnéticos ou elétricos" LYNCH, p.13, 1960.

Kevyn Lynch fala ainda que a imagem da cidade não deve estar associada simplesmente pelo seu aspecto estético e visual, mas com os atributos da identidade e da imagem mental. Além do prazer estético, elenca ainda como importantes seu significado e capacidade de expressão, ritmo, estímulos e escolhas.

A arquitetura não é percebida, pelo cego, através da agregação dos dados oferecidos pelos diferentes instantes perceptivos: como ocorre com aqueles que enxergam, não se faz bricolage de elementos. (FROIS, p. 88, 2003)

A cidade se torna então a relação entre o observador e o espaço observado. Este observador, sendo deficiente visual, pode ser treinado para assimilar os espaços e se locomover com autonomia.

"Brown nota que sujeitos de olhos vendados, aos quais foi pedido para andarem através de um labirinto, pareceu-Ihes este, de início um problema irresolúvel. Repetindo a experiência, algumas partes da estrutura, especialmente o início e o final, tornaram-se mais mais familiares e assumiram o carácter de localidades" LYNCH, p.21, 1960

A diferença cognitiva entre deficientes visuais e videntes esta relacionada a maneira como se movimentam e a sua percepção espacial. Dente modo, o conhecimento prévio dos espaços, pode ser de grande importância para seu reconhecimento e compreensão.

\section{ORGANIZAÇÃO ESPACIAL E A CIDADE}

O filósofo Denis Diderot, escreveu em sua "Carta sobre os cegos, para o uso dos que veem", dentre outras coisas, algumas questões como o cego congênito pode adquirir conhecimento. Provavelmente foi o primeiro a se preocupar em como os deficientes visuais poderiam compreender as artes e o mundo a sua volta.

Fica evidente em seu trabalho, que aos cegos a organização espacial e a manutenção da ordem é preciosa. Mais ainda, que ele necessita que cada coisa esteja em seu lugar. Exemplifica narrando qual o procedimento do deficiente visual quando chega em casa.

"Seu primeiro cuidado é pôr no lugar tudo quanto foi posto fora do lugar durante o dia; e quando sua mulher acorda, encontra comumente a casa arrumada de novo. A dificuldade 


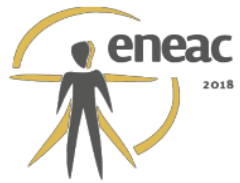

que os cegos têm em recuperar as coisas perdidas torna-os amigos da ordem" (DIDEROT, P.97, 1749)

Esta citação dá pistas de quão organizado o espaço da arquitetura da cidade tem que ser para que o deficiente visual se sinta acolhido. Compreender como se dá a percepção dos cegos pode ser o melhor caminho para se projetar uma arquitetura da cidade mais inclusiva e acessível.

"Essa acessibilidade deve estar associada à estruturação urbana que se estabelece em diferentes contextos para que, assim, haja de fato a possibilidade de exercício do direito à cidade." PEREIRA 2008

Ainda a respeito da percepção dos deficientes visuais sabe-se que, por meio de sons, cheiros e tato ele consegue distinguir as formas e, inclusive apreciar a beleza. "Ele julga da beleza pelo tato" (DIDEROT, p. 102, 1749). Percebe simetrias, ritmos e formas.

"Nosso cego julga muito bem quanto às simetrias. A simetria, que é talvez um caso de pura convenção para nós, é certamente assim, em muitos aspectos, entre um cego e os que vêem" (PULS, p.276, 2006)

Identificar a beleza não cabe apenas aos videntes, da mesma maneira os deficientes visuais também são capazes de apreciar as imagens da cidade.

"À força de estudar pelo tato a disposição que exigimos entre as partes componentes de um todo para chama-lo de belo, um cego consegue efetuar justa aplicação do termo." (PULS, p.276, 2006)

Desta maneira então, cabem aos pesquisadores e projetistas estudarem maneiras de como construir uma arquitetura da cidade mais acessível e inclusiva.

\section{COMO PROJETAR}

Para que os deslocamentos, não somente dos deficientes, possam ser realizados, os passeios públicos devem ter dimensões e ser organizados de tal maneira que possam assegurar o percurso de maneira acessível.

O projeto arquitetônico e urbanístico tem muito a contribuir neste aspecto. Frades podem ser instalados nos meio-fios das calçadas para evitar que carros estacionem sobre elas, tomando posse do espaço do pedestre; As passadeiras, ou faixa de segurança, podem ser elevadas ou mesmo podem ser projetadas rampas de acesso para se vencer o desnível; Espaços subterrâneos, como estações de metrô podem ser dotadas de elevadores e rampas; Pode ser instalado o piso tátil nos locais de todos os percursos públicos; etc.

No caso específico da pessoa com deficiência visual, há a sua disposição, alguns recursos que podem ajudar na sua acessibilidade. Os cegos percebem essa grandiosidade por meio daqueles elementos já explicitados: vento, silêncio, distribuição dos sons, cheiros etc. Não percebem a serra, mas algo que se impõe ao espírito humano; sentem-no mesmo através da sensação de liberdade que a praça instaura e que o estádio de futebol não alcança mesmo na grama, onde é possível liberdade de movimento, a monotonia de sua topografia plana rompe esse sentimento de liberdade - não se tem noção da aproximação dos limites do gramado (FROIS, p. 87, 2003)

FROIS diz ainda que muitos dos recursos necessários para a inclusão dos deficientes visuais na arquitetura da cidade são simples.

Ao longo das entrevistas, contudo, verificou-se a ocorrência de uma abordagem que não dizia respeito à utilização de técnicas ou tecnologias inusitadas, para ampliar o campo de ação preceptiva. Ao contrário, o que se verificou foi a sistemática cobrança de valores tão antigos quanto a teoria de Vitrúvio. (FROIS, P. 90-91, 2003) 


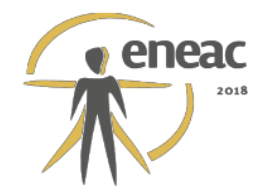

A seguir serão explorados alguns deles e será discutido a forma como alguns podem ser integrados ao espaço projetado.

\subsection{A bengala}

A bengala auxilia na orientação da pessoa com deficiência visual por meio da identificação de obstáculos. O cego tateia com a ponta da bengala o seu percurso detectando as informações necessárias ao seu deslocamento.

"Suas técnicas de uso geralmente são ensinadas por instrutores especializados em cursos de orientação e mobilidade. Para o uso da bengala deve-de aprender técnicas de varredura, deslocamento em escadas, toque e deslize da bengala, atravessar portas e de identificação de objetos como entrada de elevadores" THESBITA, p.26, 2013

$\mathrm{Na}$ figura 1 pode-se ver um exemplo de pessoa com deficiência visual fazendo seu deslocamento com o auxílio da bengala.

Figura 1 - Pessoa com deficiência visual, no deslocamento com auxílio da bengala

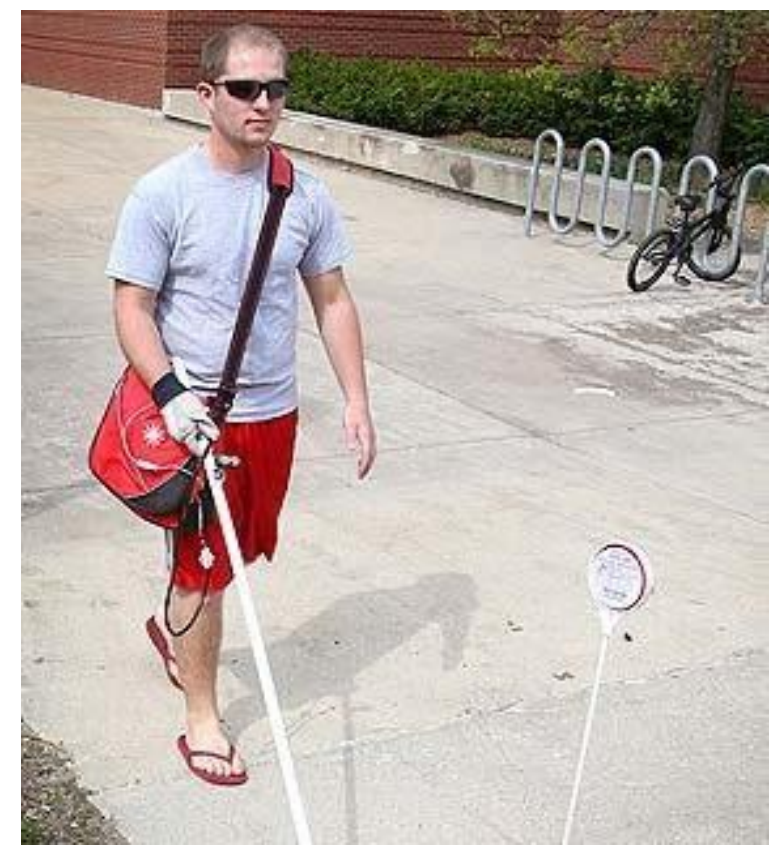

Fonte: http://cegueiraebaixavisao.blogspot.pt/2013/05/artigo-quem-inventou-bengala-branca.html

Embora este instrumento seja amplamente utilizado, ele por si só não se basta, principalmente quando a cidade não possui os recursos de sinalização necessários.

\subsection{Cão Guia}

O cão guia (Figura 2) é um animal adestrado para conduzir a pessoa com deficiência visual, auxiliando na identificação de obstáculos e caminhos. Contudo, como os cães não distinguem cores, podem ter dificuldades em interpretar informações como um semáforo por exemplo. 


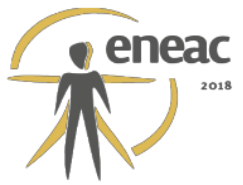

Figura 2 - Pessoa cega conduzida com auxílio do cão-guia

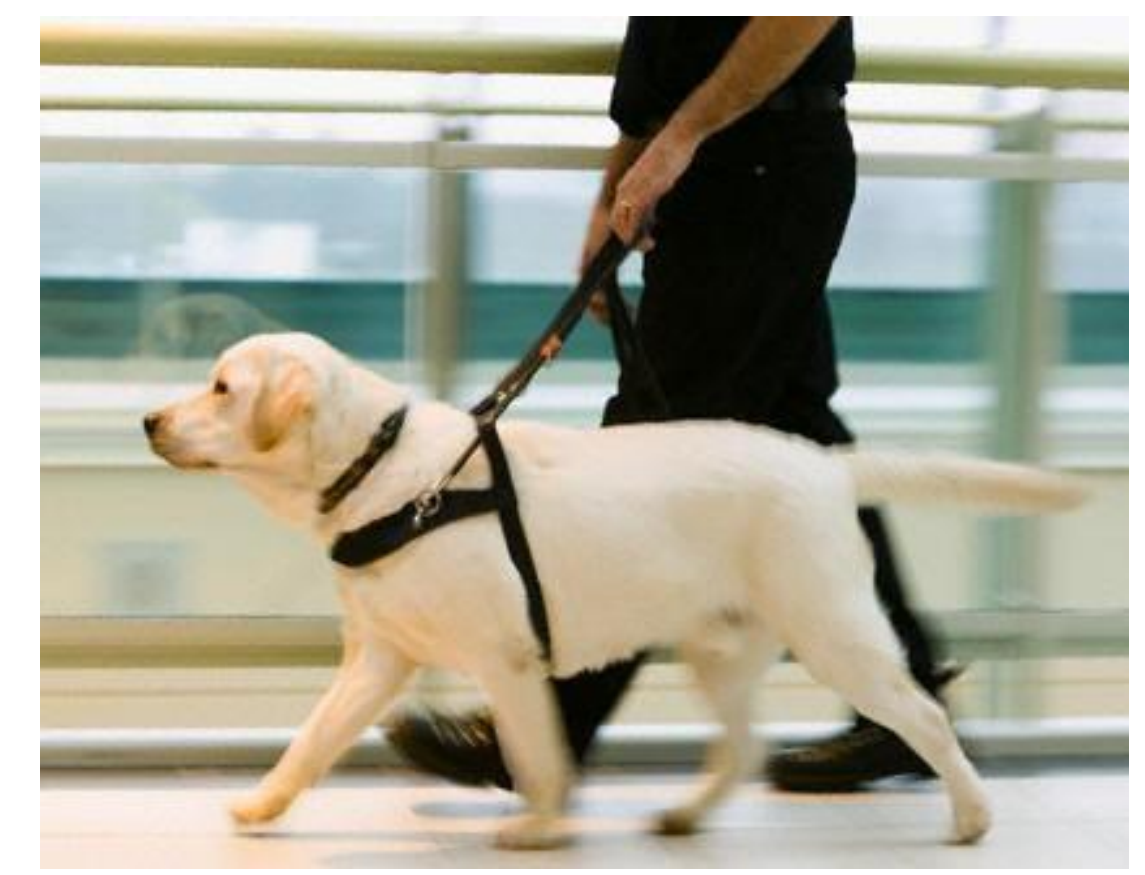

Fonte: http://2.bp.blogspot.com/-

aOTIOpN6vy4/UY4ErtquaQI/AAAAAAAAADM/BkOrQjPFMfk/s1600/cao-guia.jpg

Kevin LYNCH, no livro "Good City Form" enumera alguns subsídios que são importantes para a inclusão dos deficientes visuais, o cão guia é um deles.

"Provision free seeing-eye dogs for the blind" LYNCH, p. 199, 1984

Em Portugal, desde 1999, os ambientes públicos são obrigados por lei a receber os cegos com seus cães-guia, expresso pelo decreto de lei 118/99 de 14 de abril. Contudo ainda é raro ver o uso do cão-guia em Portugal pelos deficientes visuais.

\subsection{Sinalização sonora}

Assim como os sinos dos campanários das igrejas servem, mesmo em tempos atuais, para sinalizar o começo de uma celebração, os meios de sinalização sonora permitem a transmissão de informações, por meio do recurso auditivo.

As imagens da cidade são também feitas de sonoridades. Os sons urbanos contêm um valor heurístico que pode revelar não apenas a evolução urbana, mas também o modo actual de organização dos ambientes..." (FORTUNA, p. 21, 1998)

Apesar de poucos projetistas levarem em consideração as sonoridades da cidade, elas são um dos principais meios do deficiente visual compreender a imagem da cidade. FORTUNA, autor do artigo "Imagens da cidade: sonoridades e ambientes sociais urbanos", relata seu "redescobrir" a cidade de Nova lorque por meio de sua sonoridade

"A geografia desta metrópole (NewYork) foi-me sendo ensinada por um amigo - Anísio Correia - que, sendo invisual, me fez ver como a cidade pode ser lida e percebida através de suas paisagens e ambientes sonoros. "(FORTUNA, p. 22, 1998)

Para além dos sons "naturais" da cidade, os projetistas podem trabalhar o recurso sonoro para uma orientação universal. Exemplos assim, já são comuns nas indicações de voos em 


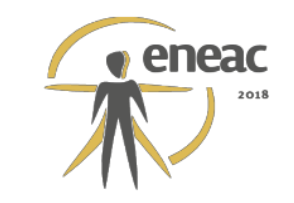

aeroportos, nas indicações das paradas do, ainda nas estações, há sinal sonoro para abrir e fechar portas, entre outros.

No tecido urbano, em alguns pontos, há semáforo sonoro que indica ao pedestre com deficiência visual o momento certo de atravessar a rua por meio de bipes. Contudo a utilização deste recurso ainda é rara.

\subsection{Piso tátil}

O piso tátil é um elemento de sinalização com relevos aplicado no piso para orientar os deficientes visuais.

"A pessoa com deficiência visual costuma guiar-se com auxílio de bastão e percebe as mudanças de ambientes através do contato com piso e paredes, por sua textura e relevo. $O$ piso tátil é usado como referência para facilitar a orientação das pessoas cegas e de baixa visão e fornecer-lhes maior segurança e autonomia.” .CAMISÃO, p.190, 2010

Os padrões de relevo de piso tátil são apenas dois: O alerta e o direcional.

O primeiro (Figura 03) é formado por placas com textura circular e serve para indicar que há um obstáculo suspenso, rebaixamento de calçada, início ou término de calçada, portas, desníveis ou mesmo que há mudança de direção no percurso.

Figura 3 - Sinalização tátil de alerta e relevos táteis instalados no piso

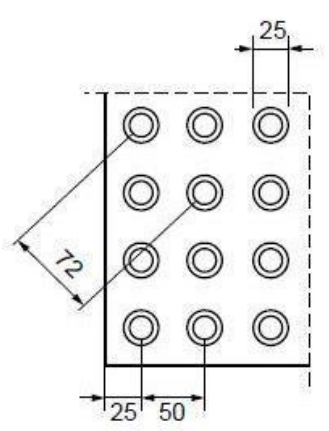

a) Piso

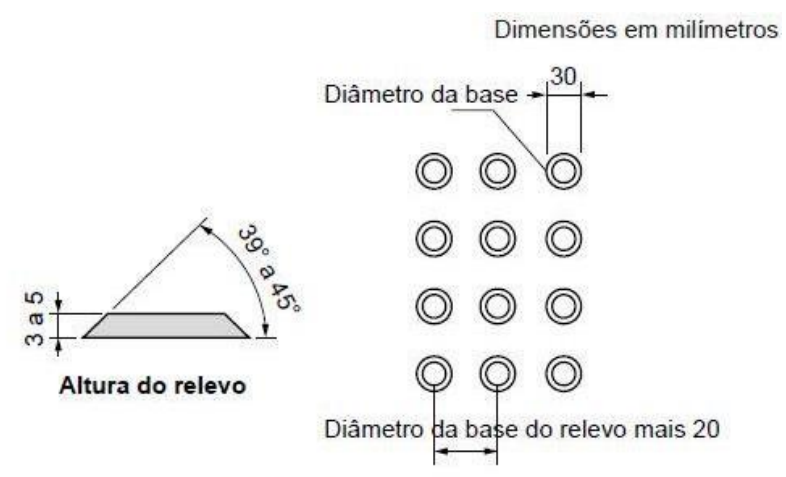

b) Relevos

Fonte: ABNT, 2015

O segundo (Figura 04) é formado por placas com textura de barras lineares regularmente dispostas. Serve para indicar a direção dos percursos possíveis sendo balizada no uso conjunto com o piso tátil de alerta. 


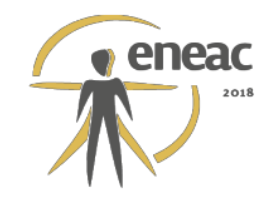

Figura 4 - Sinalização tátil direcional e relevos táteis direcionais instalados no piso
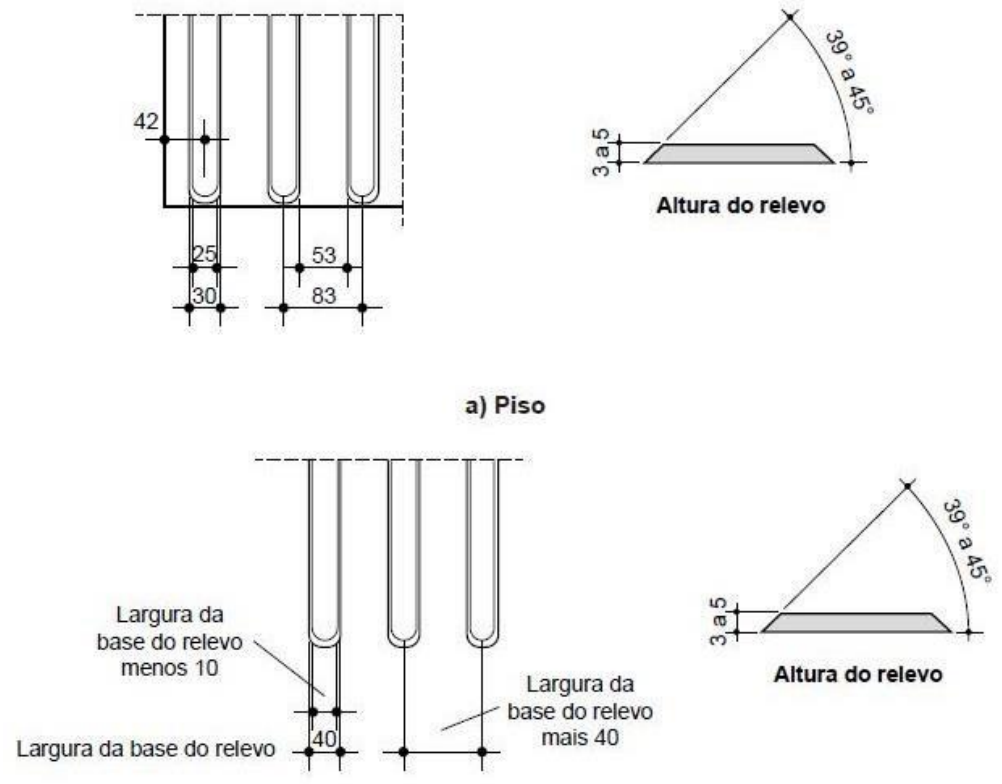

b) Relevos

Fonte: ABNT, 2015

"Os pisos táteis são faixas com superfície em relevo diferente do utilizado no restante do piso local, para que possa ser percebido com maior facilidade pelos pés e pela bengala. Nos percursos de pedestres em parques, jardins, praças, passeios e áreas amplas, que não contem com meio-fio ou linha de edificações como referência direcional, deve-se alocar um guia (faixa de orientação) para auxílio na percepção das direções. Para pessoas com baixa visão, é importante que o piso tátil seja de cor contrastante à do piso circundante, facilitando sua percepção. O piso tátil deve ser cuidadosamente alocado no projeto e instalado, de forma a não apresentar ressaltos ou qualquer incômodo aos transeuntes em geral." CAMISÃO, p.190, 2010

Na figura 5, a arquiteta Maiara Márjore MARINI, detalha como deve ser a instalação do piso tátil alerta (neste caso em vermelho) e direcional (em amarelo) em um cruzamento acessível. Vale ressaltar, que além da instalação do piso tátil, decisões de projeto inclusivo também foram contempladas como faixa de pedestre elevada, rampa acessível, proteção de esquina com barreiras (floreira e lixeiras), faixa exclusiva para ônibus, ciclofaixa, bolsões recuados de estacionamento. 


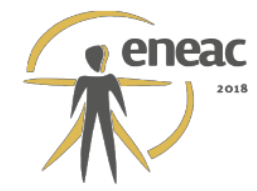

Figura 5 - Exemplo de projeto com instalação do piso tátil

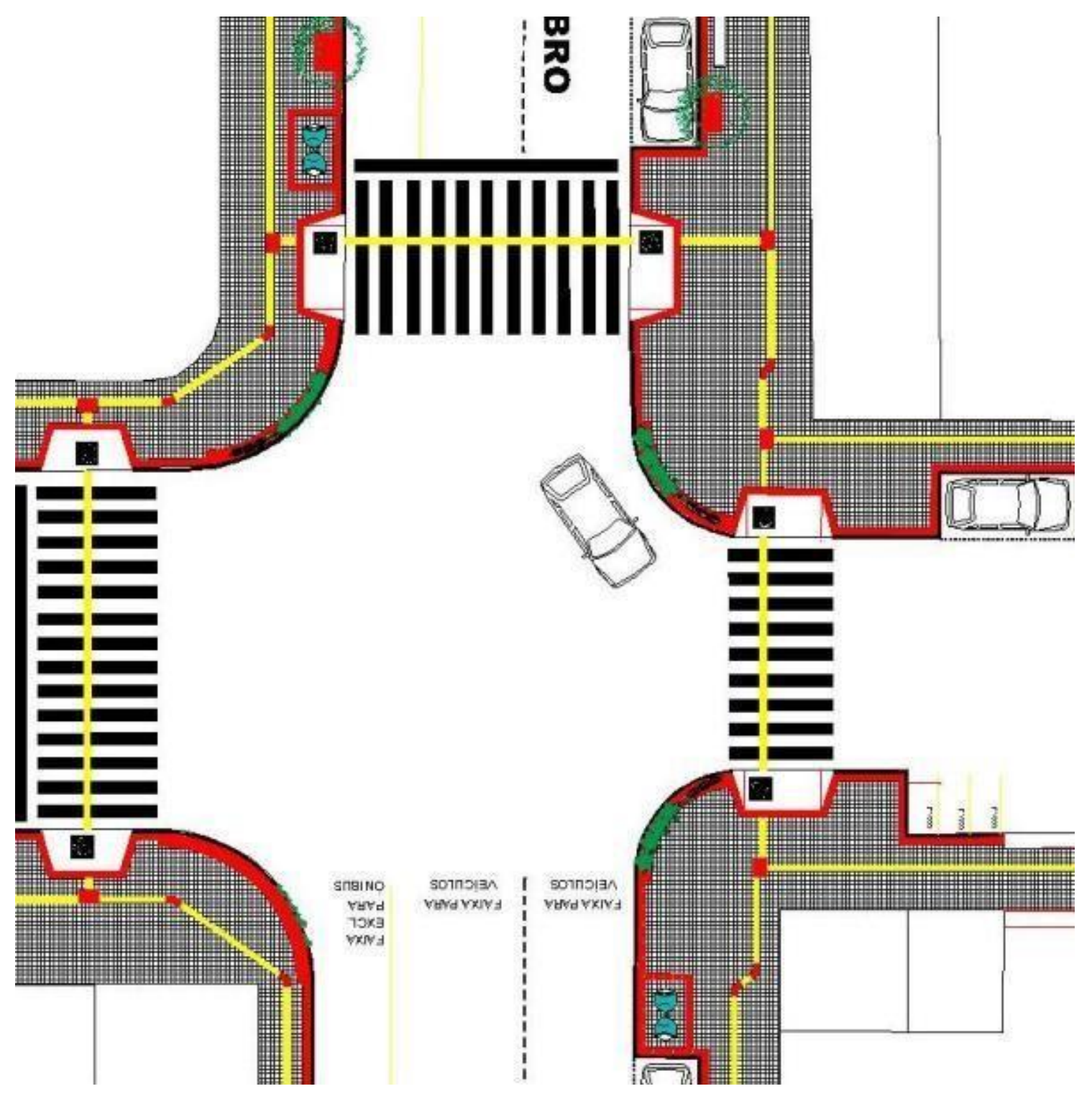

Fonte: MARINI, 2012

\subsection{Mapa tátil}

LYNCH descreve como estratégia de conhecimento prévio dos ambientes o acesso a mapas e diagramas, descreve ainda critérios de como devem ser elaborados para o observador de maneira geral.

"O mapa, quer exacto ou não, deve ser suficientemente bom para que conduza uma pessoa a casa. Deve ser suficientemente claro e bem integrado para que poupe o esforço mental: deve ser legível. Deveria ser seguro, com um excedente de indicações para que as iniciativas próprias sejam possíveis e o risco de insucesso não seja demasiado grande." LYNCH, p. 19, 1960

Ainda sobre esta estratégia de reconhecimento do espaço, LYNCH explica que a representação não precisa ser necessariamente fidedigna ao traçado original do percurso.

"Pode fornecer-se ao contemplador um diagrama simbólico da forma como o mundo se harmoniza: um mapa ou um conjunto de instruções escritas. Enquanto ele puder ajustar-se 


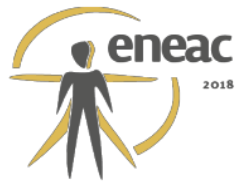

ao diagrama, possui indicações para as relações dos objetos. Poder-se-á até instalar uma máquina que indica as direcções..." LYNCH, p. 21, 1960

Conceito este confirmado pelo engenheiro Harry Beck em 1933, ao desenhar o primeiro mapa de metro de Londres que disse que representar exatamente a geografia não é apenas desnecessário, mas pode ainda escondê-la da percepção do observador.

"Exact geography is not only unnecessary for answering these kinds of questions, it can be even hindering" WOLF

Para a pessoa com deficiência visual, a forma de tornar acessível este recurso é explorando sua capacidade tridimensional para que se possa interpretá-lo por meio do recurso tátil. Este item pode ser denominado como mapa ou plano tátil.

"Mapas são representações gráficas do espaço e como abstrações da realidade pertencem ao mundo das imagens. Pessoas com deficiência visual precisam que estas imagens sejam percebidas por outros canais da percepção, substituindo a visão. Um mapa é chamado tátil quando este em um formato que permite que seja 'visto pelo toque', nesse caso, são contruídos através da linguagem gráfica tátil com signos em relevo" VASCONCELLOS, p35, 1993

A associação brasileira de normas técnicas define como os mapas táteis devem estar dispostos no espaço arquitetônico e urbano:

"5.4.2.3 Estes planos e mapas devem ser construídos de forma a permitir acesso, alcance visual e manual, atendendo à Seção 4 e 5.4.1-a). " ABNT, p. 45, 2015

"5.4.1 - a) a sinalização deve estar localizada na faixa de alcance entre 1,20 m e 1,60 m em plano vertical, conforme Figura 59. Quando instalada entre 0,90 m e 1,20 m, deve estar na parede ao lado da maçaneta em plano inclinado entre $15^{\circ}$ e $30^{\circ}$ da linha horizontal e atender ao descrito em 5.4.6.5, quando exceder 0,10 m; " ABNT, p. 44, 2015

Quanto a elaboração, a arquiteta KATAKURA, tutora do escritório modelo, conduziu um levantamento de diversos mapas táteis em São Paulo e Barcelona e concluiu:

"Avaliando as condições dos mapas instalados no Brasil, constatamos em muitos deles um processo artesanal de fabricação e uma grande diversidade de materiais empregados em sua confecção. Os mapas táteis na Espanha, já apresentam uma padronização, principalmente quando são elaborados por órgãos do governo. Com relação à conservação, o estado de conservação é adequando na maioria dos casos analisados. Com relação à resistência a intempéries, nenhum mapa levantado na cidade de São Paulo apresenta resistência." KATAKURA, 2012

A falta de padrões destes mapas pode dificultar a compreensão das informações pelos deficientes visuais. Na figura a seguir há exemplos de mapas táteis catalogados no trabalho de KATAKURA (Figura 7). 
Figura 6 - Exemplos de mapas táteis públicos

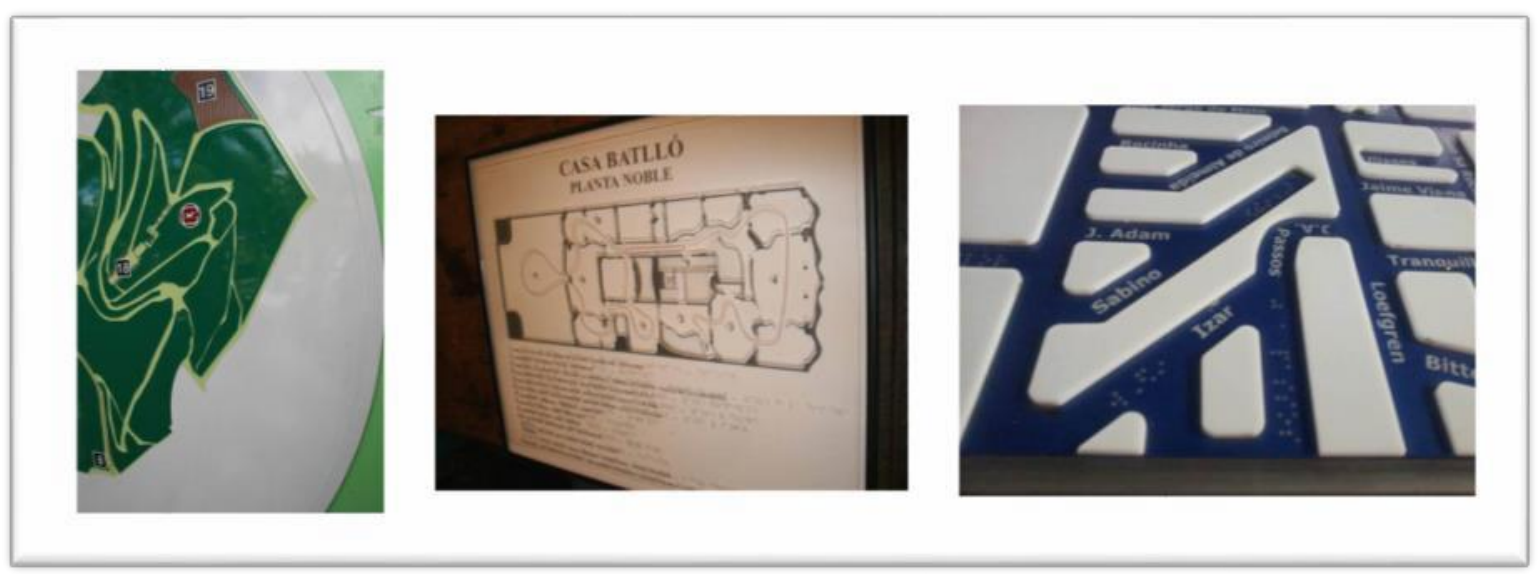

Fonte: Adaptado de KATAKURA, 2012

\section{RESULTADOS E DISCUSSÕES}

Este artigo apresentou uma revisão da literatura e sua evolução a respeito de como os elementos da arquitetura da cidade podem contribuir para a inclusão do deficiente visual e qual a maneira mais adequada de reproduzi-los. Com relação a estes elementos, tem-se que a falta de padronização dos mesmos se mostra como um agente dificultador da percepção dos mesmos. Para trabalhos futuros há a necessidade de investir em pesquisa de padronização dos mapas e pisos táteis.

\section{REFERÊNCIAS BIBLIOGRÁFICAS}

AMIRALIAN, Maria Lucia Toledo Moraes. Compreendendo o cego: Uma visão psicanalítica da cegueira por meio de desenhos-estórias. Casa do psicólogo Itda, 1997.

ASSOCIAÇÃO BRASILEIRA DE NORMAS TÉCNICAS. NBR 9050. Acessibilidade a edificações, mobiliário, espaços e equipamentos urbanos. $2^{2}$ ed. 2004

ASSOCIAÇÃO BRASILEIRA DE NORMAS TÉCNICAS. NBR 9050. Acessibilidade a edificações, mobiliário, espaços e equipamentos urbanos. $3^{\mathrm{a}}$ ed. 2015

BANERJEE, Tridib. SOUTHWORTH, Michael. City sense and city design: Writings and Projects of Kevin Lynch. 3 ed. MIT press. London. 1996

CAMISÃO, Veronica. As Cidades e a acessibilidade. In: LICHT, Flavia Boni.

SILVEIRA, Nubia. Celebrando a diversidade: Pessoas com deficiência e direito a inclusão. São Paulo, 2010.2 Disponível em:

http://www.planetaeducacao.com.br/portal/Celebrando-Diversidade.pdf

DIDEROT, Denis - Carta Sobre os Cegos- para uso dos que vêem, 1749.Coleção "Os

Pensadores"- Ed. Abril, 1979.

FORTUNA, Carlos. Imagens da cidade: sonoridades e ambientes sociais urbanos. Revista crítica de ciências sociais. No 51, 1998.

FRÓIS, Katja Plots. Mais ética, menos estética. Cadernos de arquitetura e urbanismo. V,

10. N.11, PUCMG, $2003 \quad$ Disponível em

http://periodicos.pucminas.br/index.php/Arquiteturaeurbanismo/article/view/757 


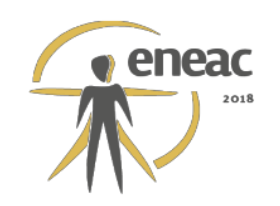

KATAKURA, Paula. Mapas táteis: levantamentos e organização de formulário. 2012. Disponível em: https://mapatatil.wordpress.com/2012/12/05/mapas-tateis-levantamentos-e- organizacao-deformulario/. Acesso em: 02 de dezembro de 2015

LYNCH, Kevin. A imagem da cidade. Edições 70. 1960

LYNCH, Kevin. Good city form. MIT, 1984.

MARINI, Maiara Marjore. Projeto piloto: Calçada para todos. 2012 Disponível em: http://pro.casa.abril.com.br/photo/projetopiloto-calcada-de-todos-1?context=user. Acesso em 18 de janeiro de 2016.

PEREIRA, Silvia Regina. Percursos Urbanos: Mobilidade espacial, acessibilidade e o direito a cidade. Barcelona, 2008 in $X$ colóquio internacional de geocrítica. Disponível em: http://www.ub.edu/geocrit/-xcol/297.htm

PULS, Mauricio. Arquitetura e filosofia. Editora Anablume. São Paulo. 2006.

THESBITA, Lucinda Domingos Bittencourt. Mapa tátil como recurso de acessibilidade à cidade: um estudo de caso na estação do metrô Santa Cruz da cidade de São Paulo. Dissertação de mestrado. 2013

GUIMARÃES, Natanael Andrade. BARBIERI, Maria Júlia. Cléo: De cegos na cidade à cidade de invisíveis. Disponível em:

http://www.webartigos.com/_resources/files/_modules/article/article_105859_201303261033 20b720.pdf. Acesso em 07 de dezembro de 2015.

VASCONCELOS, R. A. A cartografia tátil e o deficiente visual: uma avaliação das etapas de produção e uso do mapa. Tese. USP, São Paulo, 1994.

WOLFF, Alexander. Drawing subway Maps: A survey. 